\title{
Letters to medical devices: a case study on the medical device user requirements of adolescents with type 1 diabetes
}

\author{
Gillian M. McCarthy, Edgar R. Rodríguez Ramírez \& Brian J. Robinson
}

To cite this article: Gillian M. McCarthy, Edgar R. Rodríguez Ramírez \& Brian J. Robinson (2019): Letters to medical devices: a case study on the medical device user requirements of adolescents with type 1 diabetes, Behaviour \& Information Technology, DOI: 10.1080/0144929X.2019.1606939

To link to this article: https://doi.org/10.1080/0144929X.2019.1606939

Published online: 22 Apr 2019.

Submit your article to this journal $\llbracket$

View Crossmark data ¿ 


\title{
Letters to medical devices: a case study on the medical device user requirements of adolescents with type 1 diabetes
}

\author{
Gillian M. McCarthy ${ }^{\mathrm{a}}$, Edgar R. Rodríguez Ramírez ${ }^{\mathrm{a}}$ and Brian J. Robinson ${ }^{\mathrm{b}}$ \\ ${ }^{\mathrm{a} S}$ School of Design, Victoria University of Wellington, Wellington, New Zealand; ${ }^{\mathrm{b}}$ School of Nursing, Midwifery and Health, Victoria University of \\ Wellington, Wellington, New Zealand
}

\begin{abstract}
Adolescents and young adults with type 1 diabetes are required to use a variety of persuasive medical technologies to manage their health. However, adolescents' experiences with and preferences regarding these technologies, and the implications these have on self-management are not broadly recognised. In this case study of a novel method nine adolescents and young adults wrote love letters or break-up letters to one of their medical devices. Four categories of user requirements were constructed from a grounded theory analysis of the letters and followup interviews: acquiring and changing medical devices, requiring convenience and practicality for everyday contexts, collecting and using data, and corresponding with preferences and values. Young people are often excluded from research and development regarding medical devices, yet this method was successful in identifying emotional information and requirements to inform the design of medical devices.
\end{abstract}

\section{ARTICLE HISTORY}

Received 3 September 2018

Accepted 7 April 2019

\section{KEYWORDS}

type 1 diabetes; cultural probes; adolescence; medical technology

\section{Introduction}

When a person is diagnosed with type 1 diabetes they are immediately required to undergo an extensive array of behaviour changes. In essence, the person has to manually take on the role that their pancreas would otherwise perform. This range of required behaviours, referred to as self-management, is intensive. On a daily basis young people with type 1 diabetes are required to perform numerous blood glucose tests, monitor and plan their diet and exercise, and calculate and invasively self-administer insulin doses (Strawhacker 2001). When carried out as recommended by health professionals, this intensive treatment regimen delays the onset and reduces the progression of diabetes complications such as diabetic retinopathy (eye damage) and nephropathy (kidney damage) (DCCT Research Group 1994).

Many of these self-management tasks require the use of analogue and digital medical technologies. For instance, a lancet to prick the skin of a finger and draw blood, a blood glucose meter to analyse the glucose levels in a blood sample, a syringe, insulin pen or insulin pump to pierce the skin and deliver insulin, and a logbook or mobile app to track all of these measurements, dosages and behaviours. These technologies are situated within a behaviour change regimen, with behaviours spanning many of Fogg's behaviour types, with some individuals learning new behaviours, others striving to increase the frequency of self-care behaviours, and others maintaining behaviours (Fogg and Hreha 2010).

Some of these medical technologies are deliberately designed with persuasive strategies. For instance, a continuous glucose meter will alarm when blood glucose levels are too high or too low, reminding the wearer to eat to raise their blood glucose level, or administer insulin to lower their blood glucose level. Additionally, a blood glucose pen may be equipped with a screen displaying time since the last injection, ensuring the adolescent does not accidentally deliver their intended insulin dose multiple times.

Alternatively, some medical technologies do not appear to be designed using persuasive strategies. In fact, they may act as inhibitors of desired behaviours. For instance, the obvious clinical appearance and exposed needles in medical equipment can prompt unwelcome comments from peers and inhibit self-care behaviours during school hours. Understandably, engagement among adolescents with diabetes is low, with nearly two-thirds of adolescents failing to meet targets for glycaemic control; a concern for long-term health outcomes (DCCT Research Group 1994; Cameron 2006; Hilliard et al. 2013).

Diabetes management takes place alongside typical characteristics of adolescence such as biological, 
cognitive, social and emotional development within a changing context of family, peers, and school environment (Warner and Hauser 2009). This normative development results in adolescents valuing social norms and other people's perceptions of them, having difficulty anticipating the consequences of their behaviours, having feelings of invincibility, and taking risks (Elkind 1998; Millstein and Halpern-Felsher 2002; Irwin and Charles 2003). Consequently, adolescents' barriers to self-managing type 1 diabetes include fears of negative reactions from peers, pressure to fit in socially, developing independence, school issues and affective disorders (Wysocki and Greco 2006; Borus and Laffel 2010; Croom et al. 2010;Pyatak, Florindez, and Weigensberg 2013). While it is clear these characteristics of adolescence can impact diabetes management, there has been little research into how characteristics of medical devices could currently affect self-management, and how they could be designed persuasively to facilitate self-management practices.

These medical technologies occupy a space bridging clinical and consumer products and services. While devices must be clinically effective, they must also meet users' needs, so that they will be willing and able to use and purchase equipment. Designers of medical devices ought to consider users' contexts, motivations and preferences (Tatara 2009). If adolescents' priorities are in conflict with the required treatment regimen, their engagement may be affected and they can become disengaged from effective self-management (Suris, Michaud, and Viner 2004). As such, it is pertinent to explore the current effects of these medical technologies on selfmanagement, and whether persuasive strategies can be introduced more deliberately. Clinical efficacy needs to be paired with effective use: 'The most carefully designed and prescribed technology is of no value if the intended user leaves it in the closet' (Polgar 2010, 22).

Previous research has described psychosocial barriers to insulin pumps and blood glucose meters, and explored adolescents' medical device compatibility and expectations (Carroll, Downs, and Marrero 2007; Seereiner et al. 2010; McCarthy, Rodríguez Ramírez, and Robinson 2016). However, there is very little research documented in this area from a design perspective. Designers need to better understand how to elicit adolescents' experiences and user requirements in a manner that informs the design of persuasive medical technologies.

\subsection{Cultural probes and letter writing}

Although adolescents have specific requirements of medical devices, their preferences can go unrecognised by researchers, with adolescents often using technology designed for children or for adults, resulting in decreased engagement and poorer health outcomes (Carter 2009; Lang et al. 2013). Ethical restrictions around research practices with this group are viewed as a barrier (Money et al. 2011), and commonly proxies such as parents, clinicians, healthy adolescents and device designers are used in the development and validation of new medical technologies (Lang et al. 2012). Involving young people in the design of interactive technologies is an import requirement for patient-centred design (van der Velden and Culén 2013). Medical technology designed for adolescents' unfulfilled needs may also be attractive to both children and adults.

Previous studies have developed and employed user requirements to inform the design of medical and assistive technologies for a range of users with various health conditions (Milewski and Parra 2010; Owen, Buchanan, and Thimbleby 2012). The four-layer Needs and Aspirations of Design (NADI) model builds on this approach. The model classifies insights at four levels: solutions the products people want, scenarios - the interactions people want, goals - why people want these interactions, and themes - the values that drive people's goals (van der Bijl-Brouwer 2016). The deeper levels such as themes and goals are helpful for reframing design problems and opening up the solution space, while scenarios and solutions are helpful for incremental innovation and refining solutions (van der Bijl Brouwer and Dorst 2014).

This case study forms part of a larger body of research, where methods such as semi-structured interviews, card-sorting, cultural probes and design workshops were used to elicit adolescents' self-management experiences and user requirements (McCarthy 2018). This article focuses on one of the cultural probes deployed. Cultural probes were chosen to investigate both current and desired self-management experiences and user requirements of medical technologies. They were chosen over traditional observation methods that may have intensified embarrassment and stigma, causing distress. Probes rely on self-documentation, with participants taking an active role in data collection. They are characterised by being exploratory and focusing on the participant's personal context and perceptions (Mattelmäki 2006). Probes often consist of activities to be completed using resources such as maps, diaries, disposable cameras, and worksheets, and can represent a participant's personal narrative of their illness (Burrows, Mitchell, and Nicolle 2015; Mawson et al. 2014; Melles and Freudenthal 2017; Rich, Lamola, Gordon, and Chalfen 2000).

Probes are commonly used for: design inspiration, collecting information, facilitating design and research participation, and facilitating dialogue (Mattelmäki 2006). 
In this research, probes were used to contribute to information, participation, and dialogue. Alternately to the original probes approach, probes that seek to develop empathy with participants are commonly followed by interviews, allowing the researcher to check and further their interpretation of data with the individual who created it (Boehner, Vertesi, Sengers, and Dourish 2007; Gaver, Dunne, and Pacenti 1999; Gaver and Dunne 1999; Mattelmäki 2006). This participant involvement is akin to a participatory design approach, though analysis of the materials ultimately lies with the researcher (Mattelmäki 2006).

Cultural probes have previously been used to scope understand how to ethically and effectively develop persuasive technologies (Davis 2012). They have also been used in existing research with children and adolescents with type 1 diabetes. These studies demonstrate probes to be an effective way of collecting health data in private settings, though they also make clear that adolescents do not always provide emotional information unless specifically prompted (Hassling et al. 2005; Tsvyatkova and Storni 2014). People's emotional connections with technologies are important for designers to investigate as they impact perceptions of usability and functionality (Norman 2004). As such, rather than using a more commonly deployed probe such as a diary study, we adapted a letter-writing method to prompt information about emotions and relationships with technology.

This approach was adapted from a Smart Design group workshop method where participants wrote a break-up letter to a consumer product or service, then read it aloud to a group (Smart Design 2010). Variations of this method have been developed in recent years. These approaches are informed by the emotional nature of a love or break-up letter or conversation and seek to understand the relationships people have with products and services. In one variation of the method love and break-up letters were written to a library space as part of a cultural probes approach and followed by an interview (Marshall and Priestner 2016), and in another study participants were given one minute to select a technology they no longer used and prepare to liken it to a person they had broken up with (Gerber 2011). They communicated their feelings directly to a video camera as if it were the technology. Some participants completed this activity in isolation, whereas others had an audience and viewed other participants' videos.

These methodological approaches vary based on the type of product, service, or location selected, whether participants create or present their work in isolation or with researchers or an audience, how much time participants are given to prepare, and whether the activity is followed by an interview. Types of information elicited in these studies included reasons for initial use of technology, moments of change and the reasons behind these, and emotional content about features and relationships.

The aim of this case study was to trial a method of writing love letters and break-up letters to medical devices. We aimed to uncover adolescents' wide-ranging self-management experiences and psychosocial user requirements of medical technologies for the self-management of type 1 diabetes, particularly seeking to facilitate participants' emotional descriptions of their relationships with medical technology. By understanding adolescents' experiences and requirements, persuasive strategies may be able to be applied to medical technologies in more tailored and appropriate ways.

\section{Love letter, break-up letter method}

This case study comprised nine participants aged 13-24 years who had been diagnosed with type 1 diabetes for between 6 months to 15 years. Three participants were male and six were female. They were each given a cultural probes pack to complete at home over the course of two weeks containing instructions, activity cards, stationery, and an envelope for returning the activities once completed (Figure 1). Some participants kept the probes for a longer duration.

While this paper focuses only on the letter writing activity, participants were asked to complete five other probes: drawing a metaphor for diabetes management, describing ideal management, photographing a day in their life, photographing diabetes equipment and paraphernalia, and identifying the best and worst features of current medical devices (McCarthy 2018). The activity card for the letter-writing activity is pictured below (Figure 2).

Participants were requested to write either a love letter or a break-up letter to diabetes technology. The instructions read:

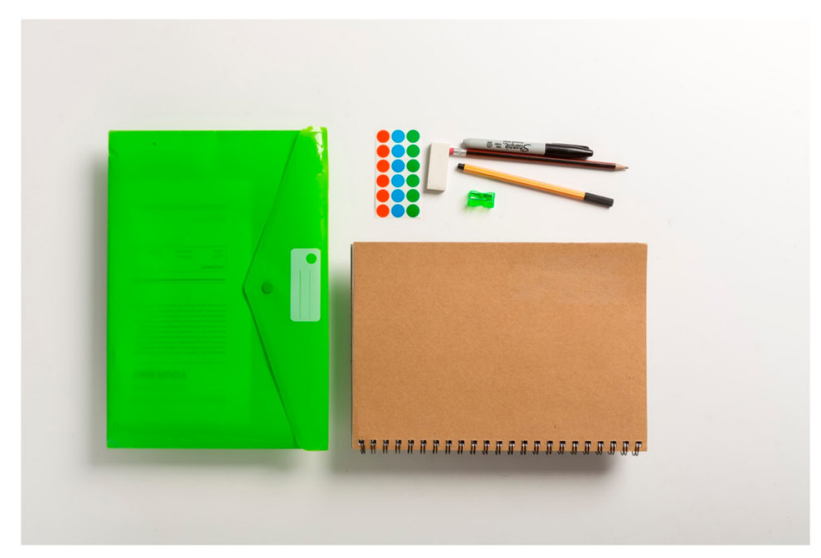

Figure 1. Cultural probes kit supplied to participants. 


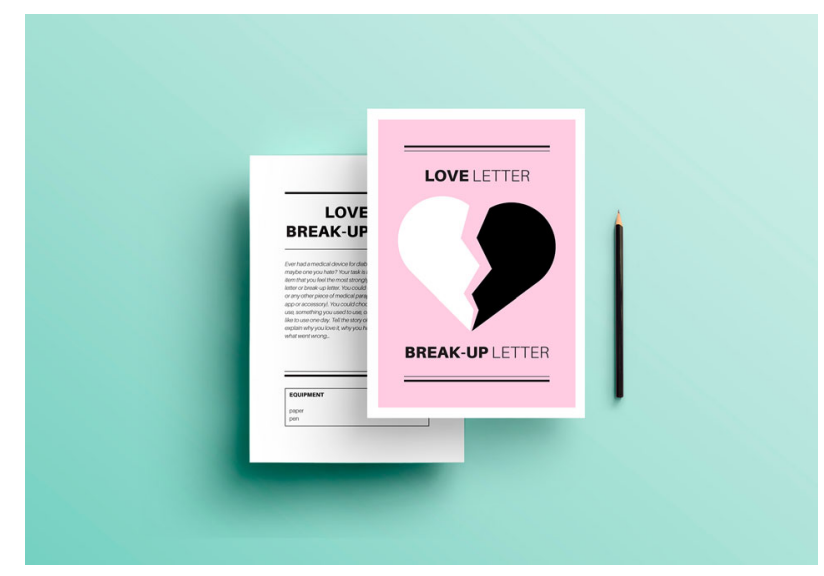

Figure 2. Activity card for letter-writing method.

Ever had a medical device for diabetes that you love, or maybe one you hate? Your task is to choose the medical item that you feel the most strongly about and write it a love letter or break-up letter. You could choose a medical device or any other piece of medical equipment (e.g. Accessory or phone app). You could choose a device you currently use, something you used to use, or something you would like to use one day. Tell the story of how you came to use it, explain why you love it, why you hate it, your expectations, what went wrong...

This activity was to be completed in the participant's own time and setting and mailed back to the researchers when completed. While nine participants completed the activity, one participant completed other probes but not this activity, describing it as 'too awkward'. A further seven adolescents were also sent cultural probes packs after agreeing to take part in the research but did not complete any activities and gave no explanation for their choice.

Participants self-selected a device to write a letter to, as previous research points towards the existence of adolescent user requirements that can be generalised across devices and medical conditions (Lang 2012). This aligned with the study's aim to find broad adolescent user requirements, and rich description of emotional experiences that other cultural probes methods can struggle to achieve (Hassling et al. 2005).

The letter-writing cultural probe was intended as a prompt for further discussion and was followed up with an interview to uncover further information and assess whether our comprehension and interpretation of the data aligned with the participants' interpretations (Thoring, Luippold, and Mueller 2013). Two participants chose to complete some of the activities during the follow-up interview rather than independently beforehand, and one participant had a parent present during the interview. The letters and interviews were analysed together using a constructivist approach to grounded theory (Charmaz 2006). This included stages of open coding, focused coding, memo writing and theory construction and has previously been outlined in full detail (McCarthy 2018).

\section{Findings}

\subsection{Letters to medical devices}

Ten letters were written by the nine participants, with one participant writing both a love letter and a breakup letter. Four break-up letters were written to blood glucose meters and one to a syringe holder. Two love letters were written to insulin pumps, one to a glucose monitoring system, one to a logbook, and one to an insulin pen. During the interviews some participants talked about multiple devices, introducing further comparison. Four letters are included in full below.

Dear, my very problematic CareSensTM N.

Though you are a very permanent fixture in my life often meeting four to six times a day, I wish I could let you go. Even though you are the cheapest way of monitoring my blood glucose we are only together because the government decided you were the best option. I don't ask much from you - just correct readings and that you stop deciding to pack it in if you get too hot or cold. Your predecessor was reliable, sleek and always functional, but alas you do not give me the same courtesy. You make me second guess myself and my health which I don't appreciate. Having an ongoing medical condition is hard enough without faulty devices and constant questions marks. Sort it out and then we can talk. You're a bit outdated.

P.S. If only you were like the devices that didn't require pricks.

Dear CareSens blood sugar meter,

You are like an uncle that no one particularly likes in the family; sometimes you are fine, but other times you just infuriate me!

Your inaccuracy is the worst thing! Often I retest to find a completely different number - which after already treating, can at times be dangerous.

Also, you must always wash your hands first before testing, but this can be so hard to do when you are out and about.

I just wish I could trust you and rely on you to be there for me, but instead I often feel as though I am second guessing you.

I realise that you are so much cheaper than other brands, but what about the future cost of complications that result from inaccurate results? I hope that you can improve and step up to the mark. It scares me with 
how wrong you can be. I need you to be in my corner = so please back me up!

Yours sincerely,

[Name]

Dear insulin pump,

I love that you came into my life! You give me flexibility, confidence and happiness. Before you I did not realise how much I felt weighed down \& suffocated by the weight of type one diabetes. I love you because you enabled me to experience in many areas of my life. I felt the freedom and confidence to travel, to eat when and what I want, to play, run and jump. To step forward in life with greater independence. Although some days are frustrating and you seem to endlessly test my patience, overall I love what you have brought into my life. Whilst having type one diabetes is no 'walk in the park', (and I would love a cure) I appreciate your presence in my life. I love how you tell me how much insulin I have onboard, can match my food to bolus and are discreet. I like no longer being restricted by $24 \mathrm{~h}$ insulin, and can instantly drop or raise my basal rates. I am more confident to try new things, to be more active, and I love the support you offer me when I am unwell. Thanks pump, here's to a long and healthy future! (Unless a cure comes along!)

Love [Name] $\mathbf{x}$

Rocket - syringe holder to inject insulin

You came into my life at such a low point and I counted on you for support. I relied on you to stay healthy and happy, where most days you did the complete opposite. I started using you when I was first diagnosed, to ease the pain when giving my injections. At first I was relieved, as I didn't have to physically inject myself, I could simply push a button. Little did I know the noise of that button would continue to cause me grief, even up until today. Every meal time I felt terrified at the thought of it, blasting my headphones to my favourite songs through my walkman just to avoid that noise. The pain wasn't any easier, as you hurt me over and over with the bounce back spring that gave me the darkest bruises I've had from injecting. I'm glad I only had you in my life for a short period of time. Even looking at you a few years back brought tears to my eyes with the horrible memories flooding back.

\subsection{User requirements of medical devices}

Four categories of user requirements were constructed in a combined grounded theory analysis of the letters and interviews: acquiring and changing medical devices, requiring convenience and practicality for everyday contexts, collecting and using data, and corresponding with preferences and values. The analysis covers both participants' prior experiences with medical devices and desires for how medical devices could be improved.

\subsection{Acquiring and changing medical devices}

Adolescents desired access to affordable medical technologies that were reliable. They were frustrated by a lack of access to desirable devices, such as the Freestyle Libre, that they admired for its speed and fewer finger pricks. 'I don't have the Freestyle Libre but I would really like to get one. It's so easy to scan and get your level without having to prick your finger. My friend has one and she can get her level before I even put the test strip in my meter.' Following a change to Government subsidies, ${ }^{1}$ many participants felt frustrated using a meter they felt was less accurate and reliable. Although other meters were available, they were unaffordable. This change in technologies felt forced upon them.

We used to have a different machine but it always worked, readings were good, always worked when hot and cold, wasn't temperamental. But then the Government was like we'll swap to this one because it's cheaper. You can still get the other one but it's insane, it costs like $\$ 50$ for a thing of strips that would last you a week ... That's a quarter of my rent. It's a constant grievance.

One participant, whose blood glucose meter was broken when a vehicle reversed over it, described another form of forced change. Her meter was replaced with a different model that she did not like.

In other instances, participants stopped using a medical device of their own accord. Reasons included moving to an insulin pen that could measure half units, and the insulin pump being described as an easier solution, minimising injections and being conceived of as a present. One participant described painful and noisy usage of a 'rocket' device intended to make injections easier after diagnosis, hiding the needle from view and injecting with the push of a button.

I didn't really like anything about it. It was quite horrible, just big and clunky. I hated the noise, it had a bit of a spring back when you chucked the needle in...I couldn't bring myself to actually inject myself, just physically push the needle in, so I mean it was good, don't get me wrong ... I just cringe from it still.

This example demonstrates the significance of considering the multi-sensory experience of using medical devices.

New devices could also help or hinder independence. For one adolescent, somewhat contrarily to previous research, his insulin pump temporarily reduced his independence as he had to learn how to use the new device and was reliant on parents for site changes. Yet, like others, the catalyst to do his own site changes happened at a diabetes camp.

While one participant wrote about her reluctance at the permanence of a medical device in her life, 'Though 
you are a very permanent fixture in my life - often meeting four to six times a day, I wish I could let you go', another described her wish for a device to have a continued presence in her life if necessary 'Here's to a long and healthy future!' (Unless a cure comes along!).

\subsection{Requiring convenience and practicality for everyday contexts}

Adolescents discussed their functional demands of medical technologies within specific contexts, their preferences, and the inconvenience of carrying medical equipment. The functions available on medical devices affected how they were used in everyday contexts. For instance, while a blood glucose meter that did not make any beeping noises or have a light was discreet, it was also challenging to use at night, or when sleeping in a shared room. 'It was real flat and really fancy, but I think that they went too far and forgot the basic things.' Convenience was important, with one lancing device described positively because it required only a one-button push to deploy. Helpful features of insulin pumps included showing how much insulin remained in the pump, calculating an insulin bolus to match food, and sites that worked for a week despite health professionals recommending they were changed every three days. Helpful features of insulin pens included cartridges that lasted 3-4 weeks, dosing half units, and showing last dosage and time since last injection.

There were mixed feelings about insulin pens versus insulin pumps. Pens do not require constant, invasive attachment, but must be carried and take time to use. Insulin pumps do not require multiple needle insertions and are easy to use in many situations (e.g. in a moving vehicle), but require backup equipment to be carried.

Participants described the inconvenience of carrying medical devices and consumables with them. Insulin pumps and blood glucose meters were described as 'chunky' and 'uncomfortable'. While there was a desire for these devices to be smaller or more streamlined, the screen size needed to be legible. Adolescents stored devices in pockets, small bags or their bra, and could forget items if regularly switching bags.

One participant described how she does not always take her medical equipment with her. She was aware that there may be emergency situations where she would need the devices but had coincidentally been 'fine' in the past, happening to have her equipment when an earthquake struck, and she could not easily return to her home $50 \mathrm{~km}$ away. This behaviour typifies adolescents' propensity for risk-taking, one of the many features of normative adolescent development that interacts with managing a long-term condition (Warner and
Hauser 2009). It reflects adolescent prioritising of shortterm benefits over possible consequences with a low-likelihood. Fear of medical devices breaking also arose, with one participant using disposable insulin pens rather than reusable ones while travelling, reasoning that she would have a stockpile of pens if one broke.

\subsection{Collecting and using data}

Participants discussed the accuracy of data and needing to trust medical devices, a desire for meaningful information, and sharing data with other people. The poor reliability and accuracy of blood glucose meters was described as a major frustration.

The amount of inaccurate numbers you've had makes you second guess every single number, and so that really does play on your mind and you end up being a little bit more conservative with your corrections or your actions so then you run the risk of still being too high or too low.

She elaborated: 'It scares me with how wrong you can be.' Participants' confidence in the meter eroded over time and led them to second-guess both the accuracy of the device and their own bodily feelings, making decisionmaking difficult.

When faced with a reading that did not match the way she felt, one participant would use a spare meter then calculate insulin dosage based on which reading best represented how she currently felt. Consecutive measurements could differ by up to $18 \mathrm{mmol} / \mathrm{L}$, which is clinically significant (Craig et al. 2011). While adolescents often did not wash their hands with soap and water before use as instructed, this could be challenging based on context, such as needing to use the device while working on a farm or while cycling, and other meters were compatible with hand sanitisers, which was more convenient.

The old Optium meters were fine. I used to use hand sanitiser all the time, but with this one you can't... I live on a farm when I go home. So if you're out all day on the bike or on the farm where's your soap and water? I think it's stupid, you know we don't live in these perfect worlds where you have a bathroom nearby all the time.

Insulin pumps could also be unreliable, as insulin delivery lapsed if the insulin or battery ran out, although the pump alerted in advance. One participant found the correction calculation on his pump was inaccurate and resultantly he had to compute this calculation manually. In contrast, some adolescents did not experience reliability issues with their devices and trusted them.

Adolescents described a desire for data to be transformed into meaningful information. One wanted a 
glucose monitoring system that would regularly collect and visualise her blood glucose levels. Seeing trends would help her understand how her blood glucose levels fluctuate overnight. Another participant felt features of her blood glucose meter, such as arrows for high and low levels, may be more helpful to people recently diagnosed with diabetes who did not have an insulin pump. This illustrates the importance of not only supplying data, but also transforming it into meaningful information. Others were pleased that their insulin pens and logbooks allowed them to check when they last injected.

Participants also discussed sharing blood glucose monitoring data with parents and health professionals. One participant thought a non-invasive blood glucose monitor would allow her parents to check her levels at night if concerned. While another participant wanted to gain insights by sharing a log of her blood glucose data with a health professional, frustratingly, her blood glucose meter stopped providing data for a day because it was not within the required functioning temperature range. This participant attempted to warm the meter by putting it under her blanket and on her cat. While she was reasonably confident that she could tell without the blood glucose meter whether she was within the target range, she was also frustrated there was an entire day of her log data missing, and how the health professional would react to this missing data. 'She'll probably tell me off but it's not my fault. I actually put a little disclaimer in my spreadsheet like 'um, did intend to do it this day, didn't actually work, sorry.'

\subsection{Corresponding with preferences and values}

This category outlines two aspects: adolescents' thoughts about attention garnered by medical devices, and the level of fit between individuals and their medical devices. As medical devices for type 1 diabetes are used in many contexts, their appearances and discreetness were described as important factors. One participant valued her blood glucose meter not making any noise and drawing attention in particular contexts, while another described how her insulin pump was more discreet to use in public than injecting insulin using a pen. Participants voiced a preference for their medical devices to appear visually more like sleek, slim consumer devices. A participant described the challenge of finding medical technology that suited her aesthetic preferences when moving into young adulthood 'I feel it's hard the older you get to find things that don't look like they were made for children ... it doesn't necessarily have to be discreet but as long as it just kind of blends in with everything else.'
Disposable insulin pens and blood glucose meters and lancets were criticised as feeling 'cheap' due to materials, screens, and faulty functions. Participants desired functionality and aesthetics in tandem. In addition to aesthetic preferences, it was important for medical devices to correspond with people's broader values. For instance, one participant described wanting to replace her disposable insulin pen with a reusable one to be more environmentally sustainable, and spoke about how issues around waste and recycling were often raised by her flatmate. While this participant previously preferred to have disposable insulin pens for travelling, her priorities and corresponding device preference had now changed.

When a medical technology is well-matched to a user's needs, it can facilitate positive feelings and life experiences. Writing about her insulin pump, one participant wrote, 'You give me flexibility, confidence and happiness... I love you because you enabled me to experience in many areas of my life.' Accordingly, this participant saw her device as not only administering insulin, but also allowing her the freedom to live her life unhampered by diabetes.

\section{Discussion}

This case study explored a letter-writing technique to investigate young people's experiences with and requirements for medical devices to self-manage type 1 diabetes. As outlined above, this approach resulted in letters that communicated adolescents' experiences, expectations, desires, moments of change, and their emotional responses to technologies. These letters were also effective as prompts for further discussion in a follow-up interview.

The combination of writing love letters or break-up letters and a follow-up interview revealed information about adolescents' and young adults' experiences with medical devices and their expectations for these devices to function allowing them to effectively self-manage their long-term condition. The information gathered ranged from very specific (e.g. button noises) to broader feelings (e.g. confidence). The letter writing alone resulted in insights at all four levels of the NADI model (van der Bijl-Brouwer 2016). For blood glucose monitoring, a solution was a meter that did not require finger pricks, a scenario was the ability to function reliably at a range of temperatures, an important goal was to give users confidence to make diabetes-related decisions, and a broad theme was managing blood glucose effectively. As discussed previously, themes and goals, are helpful for reframing design problems and opening up the solution space, while scenarios and solutions are helpful for incremental innovation and 
refining solutions (van der Bijl Brouwer and Dorst 2014). We suggest that having participants write letters to a range of medical devices also contributed to the development of themes and goals, whereas for research focusedinvestigating on incremental innovation, a single device may be preferable.

While the method used in this study successfully elicited required information, the number of participants was small, necessitating the need to conduct further research to check the effectiveness of the method across a larger population and whether the resulting requirements and experiences can be generalised. Although nine participants completed the letter-writing activity, one participant objected to the method, and another seven participants in the wider research project completed no cultural probes. As such, the number of research activities and the time at which they are delivered must be carefully considered to balance the retrieval of information with participants' availability.

While eight participants wrote letters in their own time and privacy, one participant chose to write the letter during the follow-up interview. This letter was written in bullet-points as she spoke with the researcher, explaining what she was writing. This variation better suited the participant who had struggled to make time to complete the cultural probes at home, but who wanted to participate in the research. Some participants described the activities as fun, and one asked that some of his activities be returned to him, as he was proud of what he had produced.

In one case, while the majority of the letter was beneficial for the research, in select instances the participant favoured the medium of the letter more than the accuracy of the content. He wrote to his insulin pen, 'Your curves are magnificent, they make me wish I had a high blood glucose level constantly so I could always be with you.' In this instance, it was important to gauge in the follow-up interview the extent to which the statements made were accurate. In the study by Gerber (2011), participants were given limited time to devise video-recorded letters to technology. The researchers argued that giving participants a longer period of time may lead to them creating well-written but less accurate letters. This one instance supports this statement, though the other participants did not appear to struggle balancing true statements with the medium of a letter. Expectations around the desire for accurate information must be communicated to participants to ensure the resulting letters are beneficial for the research.

There was initially a concern by the researchers that writing a break-up letter to a device that participants were required to use could be distressing. To alleviate this, participants were free to choose whether to write a love letter or a break-up letter to a device of their choice. During the follow-up interview some participants reported enjoying the activity and finding it cathartic.

This case study outlined an approach to uncovering experiences and user requirements. In this instance, participants were people with significant prior experience with the devices. It appears that while some medical technologies are designed with persuasive strategies to facilitate self-management behaviours, aspects of others may even inhibit desired behaviours. As such, uncovering insights using this approach may allow device designers to eventually select and implement appropriate persuasive strategies to encourage self-management behaviours and to identify and eliminate factors that inhibit these behaviours. Further, the approach may aid in forming an understanding of people's expectations of medical devices, which can currently be misaligned with their reality (McCarthy 2016).

\section{Conclusion}

This paper trialled love and break-up letter writing to explore adolescents' medical device experiences and user requirements. Four user requirements were constructed: acquiring and changing medical devices, requiring convenience and practicality for everyday contexts, collecting and using data, and corresponding with preferences and values. The research suggests that adolescents do have strong emotional feelings about their medical technologies, and that these can be elicited through letter writing. This approach has potential for uncovering rich, qualitative information that may be of use to designers. While this case study focused only on a small group of participants using medical devices, further research should be conducted to assess the merits of this approach in wider research contexts.

\section{Note}

1. Pharmac, the New Zealand Government drug purchasing and funding agency who choose which medical devices and consumables are subsidised moved to a single supplier arrangement for blood glucose monitors and test strips in 2013.

\section{Disclosure statement}

No potential conflict of interest was reported by the authors.

\section{References}

Boehner, Kirsten, Janet Vertesi, and Phoebe Sengers. 2007. "How HCI Interprets the Probes." In Proceedings of theSIGCHI Conference on Human Factors in Computing 
Systems, CHI '07, 1077-1086. New York, NY: ACM. https:// doi.org/10.1145/1240624.1240789.

Borus, Joshua S., and Lori Laffel. 2010. “Adherence Challenges in the Management of Type 1 Diabetes in Adolescents: Prevention and Intervention." Current Opinion in Pediatrics 22 (4): 405-411. doi:10.1097/MOP. 0b013e32833a46a7.

Burrows, Alison, Val Mitchell, and Colette Nicolle. 2015. "Cultural Probes and Levels of Creativity." In Proceedings of the 17th International Conference on Human-Computer Interaction with Mobile Devices and Services Adjunct, 920923. Copenhagen: ACM.

Cameron, F. 2006. “Teenagers with Diabetes: Management Challenges." Australian Family Physician 35 (6): 386-390.

Carroll, Aaron E., Stephen M. Downs, and David G. Marrero. 2007. "What Adolescents With Type I Diabetes and Their Parents Want From Testing Technology: A Qualitative Study." CIN: Computers, Informatics, Nursing 25 (1): 23-29.

Carter, B. 2009. “Tick Box for Child? The Ethical Positioning of Children as Vulnerable, Researchers as Barbarians and Reviewers as Overly Cautious." International Journal of Nursing Studies 46 (6): 858-864. doi:10.1016/j.ijnurstu. 2009.01.003.

Charmaz, K. 2006. Constructing Grounded Theory: A Practical Guide Through Qualitative Analysis. 1st ed. London: Sage.

Craig, M. E., S. M. Twigg, K. C. Donaghue, N. W. Cheung, F. J. Cameron, J. Conn, A. J. Jenkins, and M. Silink. 2011. National Evidence-Based Clinical Care Guidelines for Type 1 Diabetes in Children, Adolescents and Adults. Canberra: Australian Government Department of Health and Ageing. http://www.apeg.org.au/portals/0/guidelines1.pdf.

Croom, Andrea, Deborah J. Wiebe, Cynthia A. Berg, Rob Lindsay, David Donaldson, Carol Foster, Mary Murray, and Michael T. Swinyard. 2010. "Adolescent and Parent Perceptions of Patient-centered Communication While Managing Type 1 Diabetes." Journal of Pediatric Psychology 36 (2): 206-215.

Davis, Janet. 2012. "Early Experiences with Participation in Persuasive Technology Design." In Proceedings of the 12th Participatory Design Conference: Research Papers Volume 1, 119-128. PDC '12. New York: ACM. doi:10. $1145 / 2347635.2347653$.

Diabetes Control and Complications Trial Research Group. 1994. "Effect of Intensive Diabetes Treatment on the Development and Progression of Long-term Complications in Adolescents with Insulin-dependent Diabetes Mellitus: Diabetes Control and Complications Trial." The Journal of Pediatrics 125 (2): 177-188. doi:10. 1016/S0022-3476(94)70190-3.

Elkind, David. 1998. All Grown up and No Place to Go: Teenagers in Crisis. Revised. Cambridge, MA: Da Capo Press.

Fogg, B. J., and Jason Hreha. 2010. "Behavior Wizard: A Method for Matching Target Behaviors with Solutions." In Persuasive Technology, 117-131. Springer. http://link. springer.com/chapter/10.1007/978-3-642-13226-1_13.

Gaver, William, and Anthony Dunne. 1999. "Projected Realities: Conceptual Design for Cultural Effect." In Proceedings of the SIGCHI Conference on Human Factors in Computing Systems, 600-607. Pittsburgh: ACM. doi:10. $1145 / 302979.303168$.
Gaver, Bill, Tony Dunne, and Elena Pacenti. 1999. "Design: Cultural Probes.” Interactions 6 (1): 21-29. doi:10.1145/ 291224.291235.

Gerber, Elizabeth. 2011. “Tech Break Up: A Research Method for Understanding People's Attachment to Their Technology." In Proceedings of the 8th ACM Conference on Creativity and Cognition, Atlanta, 137-146.

Hassling, Linda, Sam Nordfeldt, Henrik Eriksson, and Toomas Timpka. 2005. "Use of Cultural Probes for Representation of Chronic Disease Experience: Exploration of an Innovative Method for Design of Supportive Technologies." Technology \& Health Care 13 (2): 87-95.

Hilliard, Marisa E., Yelena P. Wu, Joseph Rausch, Lawrence M. Dolan, and Korey K. Hood. 2013. "Predictors of Deteriorations in Diabetes Management and Control in Adolescents With Type 1 Diabetes." Journal of Adolescent Health 52 (1): 28-34. doi:10.1016/j.jadohealth.2012.05.009.

Irwin, J., and E. Charles. 2003. "Adolescent Health at the Crossroads: Where Do We Go From Here?" Journal of Adolescent Health 33 (1): 51-56. doi:10.1016/S1054-139X (03)00143-5.

Lang, Alexandra R. 2012. "Medical Device Design for Adolescents." EThesis. http://eprints.nottingham.ac.uk/ $12501 /$.

Lang, Alexandra R., Jennifer L. Martin, Sarah Sharples, and John A. Crowe. 2013. "The Effect of Design on the Usability and Real World Effectiveness of Medical Devices: A Case Study with Adolescent Users." Applied Ergonomics 44 (5): 799-810. doi:10.1016/j.apergo.2013.02. 001.

Lang, Alexandra R., Jennifer L. Martin, Sarah Sharples, John A. Crowe, and Elizabeth Murphy. 2012. "Not a Minor Problem: Involving Adolescents in Medical Device Design Research." Theoretical Issues in Ergonomics Science 15 (2): 181-192. doi:10.1080/1463922X.2012.678910.

Marshall, David, and A. Priestner. 2016. Snapshot: A Cultural Probe Study Exploring the Research and Information Behaviour of Postdocs and PhD Students at the University of Cambridge. Cambridge: University of Cambridge.

Mattelmäki, Tuuli. 2006. Design Probes. Helsinki: University of Art and Design Helsinki. http://urn.fi/URN:ISBN:951-558212-1.

Mawson, Susan, Nasrin Nasr, Jack Parker, Huiru Zheng, Richard Davies, and Gail Mountain. 2014. "Developing a Personalised Self-Management System for Post Stroke Rehabilitation; Utilising a User-Centred Design Methodology." Disability and Rehabilitation: Assistive Technology 9 (6): 521-528.

McCarthy, Gillian M. 2018. Dear My Very Problematic Blood Glucose Meter: Adolescents' Experiences Self-Managing Type 1 Diabetes and Their Psychosocial User Requirements of Medical Technologies. Wellington: Victoria University of Wellington. http://researcharchive.vuw.ac.nz/handle/ $10063 / 6975$.

McCarthy, G. M., E. R. Rodríguez Ramírez, and B. J. Robinson. 2016. "Dissonant Technologies: Health Professionals' Impressions of Adolescents' Interactions with Medical Technologies for Managing Type 1 Diabetes." In WellBeing 2016: Co-Creating Pathways to Well-Being, 36-39. Birmingham: Birmingham City University.

McCarthy, Gillian M., Edgar R. Rodríguez Ramírez, and Brian J. Robinson. 2016. "Dissonant Technologies: Health 
Professionals' Impressions of Adolescents' Interactions with Medical Technologies for Managing Type 1 Diabetes." In Well-Being 2016: Co-creating Pathways to Well-being, 3639. Birmingham: Birmingham City University.

Melles, Marijke, and Adinda Freudenthal. 2017. "Next Generation Equipment in the Intensive Care Unit: Data Collection for Design Guidelines." Conference on Human Decision Making and Manual Control, Linköping University, June 2-4, 2003. http://repository.tudelft.nl/ islandora/object/uuid:ce4adccc-c550-4595-9953-

30148c3f4d0a/datastream/OBJ/view.

Milewski, Jim, and Hector Parra. 2010. "Gathering Requirements for a Personal Health Management System." In Proceedings of the 12th ACM International Conference Adjunct Papers on Ubiquitous Computing Adjunct, 415-416. UbiComp '10 Adjunct. New York: ACM. doi:10.1145/1864431.1864464.

Millstein, Susan G, and Bonnie L Halpern-Felsher. 2002. "Perceptions of Risk and Vulnerability." Journal of Adolescent Health Adolescent Risk and Vulnerability 31 (1, Suppl. 1): 10-27. doi:10.1016/S1054-139X(02)00412-3.

Money, Arthur G., Julie Barnett, Jasna Kuljis, Michael P. Craven, Jennifer L. Martin, and Terry Young. 2011. "The Role of the User Within the Medical Device Design and Development Process: Medical Device Manufacturers' Perspectives." BMC Medical Informatics and Decision Making 11 (1): 15. doi:10.1186/1472-6947-11-15.

Norman, Donald A. 2004. Emotional Design Why We Love (or Hate) Everyday Things. New York: Basic Books.

Owen, Tom, George Buchanan, and Harold Thimbleby. 2012. "Understanding User Requirements in Take-Home Diabetes Management Technologies." In Proceedings of the 26th Annual BCS Interaction Specialist Group Conference on People and Computers, 268-273. British Computer Society. http://dl.acm.org/citation.cfm?id = 2377950.

Polgar, Jan Miller. 2010. “The Myth of Neutral Technology.” In Design and Use of Assistive Technology, edited by Meeko Mitsuko K. Oishi, Ian M. Mitchell, and H. F. Ven der Loos, 17-23. New York: Springer.

Pyatak, Elizabeth A., Daniella Florindez, and Marc J. Weigensberg. 2013. "Adherence Decision Making in the Everyday Lives of Emerging Adults with Type 1 Diabetes." Patient Preference and Adherence 7: 709.

Rich, Michael, Steven Lamola, Jason Gordon, and Richard Chalfen. 2000. "Video Intervention/Prevention Assessment: A Patient-Centered Methodology for Understanding the Adolescent Illness Experience." Journal of Adolescent Health 27 (3): 155-165.

Seereiner, Sabine, Kurt Neeser, Christian Weber, Karsten Schreiber, Wolfgang Habacher, Ivo Rakovac, Peter Beck, Louise Schmidt, and Thomas R. Pieber. 2010. "Attitudes Towards Insulin Pump Therapy among Adolescents and Young People." Diabetes Technology \& Therapeutics 12 (1): 89 .
Smart Design. 2010. "Breakup Letter Creative Meeting." Presented at the IIT Design Research Conference, IIt Institute of Design, Chicago, May 11

Strawhacker, Mt. 2001. "Multidisciplinary Teaming to Promote Effective Management of Type 1 Diabetes for Adolescents." Journal of School Health 71 (6): 213-217. doi:10.1111/j.1746-1561.2001.tb01318.x.

Suris, J.-C., P.-A. Michaud, and R. Viner. 2004. "The Adolescent with a Chronic Condition. Part I: Developmental Issues." Archives of Disease in Childhood 89 (10): 938-942. doi:10.1136/adc.2003.045369.

Tatara, Naoe. 2009. "Designing Mobile Patient-Centric SelfHelp Terminals for People with Diabetes." In Proceedings of the 11th International Conference on Human-computer Interaction with Mobile Devices and Services, 97. ACM. http://dl.acm.org/citation.cfm?id = 1613970 .

Thoring, Katja, Carmen Luippold, and Roland M. Mueller. 2013. "Opening the Cultural Probes Box: A Critical Reflection and Analysis of the Cultural Probes Method." In 5th International Congress of International Association of Societies of Design Research, 597-603. Tokyo.

Tsvyatkova, Damyanka, and Cristiano Storni. 2014. "Investigating Issues Related to Pediatric Diabetes Education: Problems and Barriers." In Proceedings of the 8th International Conference on Pervasive Computing Technologies for Healthcare, PervasiveHealth'14, 191-194. Brussels, Belgium: ICST (Institute for Computer Sciences, Social-Informatics and Telecommunications Engineering). https://eudl.eu/doi/10.4108/icst.pervasivehealth.2014. 254935.

van der Bijl-Brouwer, Mieke. 2016. "The Challenges of Human-centred Design in a Public Sector Innovation Context." In DRS 2016 International Conference: FutureFocused Thinking. The Design Research Society. http:// www.drs2016.org/s/294-van-der-Bijl-Brouwer.pdf.

van der Bijl Brouwer, Mieke, and Kees Dorst. 2014. "How Deep Is Deep? A Four-layer Model of Insights into Human Needs for Design Innovation." In Design and Emotion. Ediciones Uniandes. https://opus.lib.uts.edu.au/ handle/10453/33538.

van der Velden, Maja, and A. Culén. 2013. "Designing Privacy with Teenage Patients: Methodological Challenges." In Submitted to CHI 2013 Workshop on Designing for and with Teenagers. http://www.kulu.no/pubs/velden_culen_ chi13_2013.pdf.

Warner, Dorothy E., and Stuart T. Hauser. 2009. "Unique Considerations When Treating Adolescents with Chronic Illness." In Behavioral Approaches to Chronic Disease in Adolescence, edited by William T. O'Donohue, 15-28. New York: Springer. http://link.springer.com/chapter/10. 1007/978-0-387-87687-0_3.

Wysocki, Tim, and Peggy Greco. 2006. "Social Support and Diabetes Management in Childhood and Adolescence: Influence of Parents and Friends." Current Diabetes Reports 6 (2): 117-122. doi:10.1007/s11892-006-0022-y. 